\title{
Revision der Lehre von der objektiven Zurechnung
} Eine Analyse zurechnungsausschließender Topoi beim vorsätzlichen Erfolgsdelikt

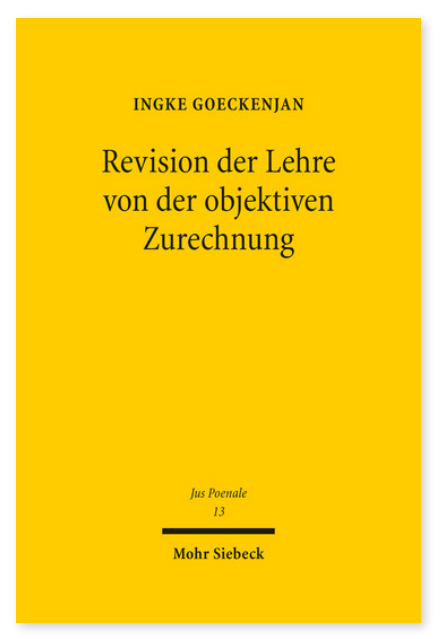

2017. XI, 331 Seiten. JusPoen 13

ISBN 978-3-16-153578-9

DOI 10.1628/978-3-16-153578-9

eBook PDF 104,00€

ISBN 978-3-16-153454-6

Leinen $104,00 €$
Nach der Lehre von der objektiven Zurechnung ist ein strafrechtlicher Erfolg nur dann als Werk des Handelnden anzusehen, wenn neben den herkömmlichen Tatbestandsmerkmalen - Handlung, Erfolg und Kausalität - zusätzliche, wertende Kriterien erfüllt sind: Der Erfolg sei nur dann objektiv zurechenbar, wenn der Täter ein rechtlich missbilligtes Risiko geschaffen habe, das sich im tatbestandlichen Erfolg realisiere. Diese Voraussetzungen sollen gleichermaßen für Fahrlässigkeits- wie für Vorsatzdelikte gelten. Ingke Goeckenjan unterzieht diese mittlerweile herrschende Auffassung im strafrechtlichen Schrifttum einer kritischen Analyse. Im Mittelpunkt der Untersuchung steht dabei eine Auseinandersetzung mit der Frage, ob und inwiefern die drei gängigen zurechnungsausschließenden Topoi (fehlende Risikoschaffung, Handeln innerhalb des erlaubten Risikos, Risikoverringerung) auch für das Vorsatzdelikt Berechtigung beanspruchen können.

Ingke Goeckenjan geboren 1974; Studium der Rechtswissenschaft an der Universität Trier und der Freien Universität Berlin; 1999 Erste Juristische Staatsprüfung; Referendariat beim Kammergericht Berlin; 2002 Zweite Juristische Staatsprüfung; 2004 Promotion zur Dr. iur.

an der Freien Universität Berlin; 2013 Habilitation an der Universität Osnabrück; seit 2014 Inhaberin eines Lehrstuhls für Strafrecht und Strafprozessrecht an der Ruhr-Universität Bochum.

Jetzt bestellen:

https://mohrsiebeck.com/buch/revision-der-lehre-von-der-objektiven-zurechnung-9783161535789?no_cache=1 order@mohrsiebeck.com

Telefon: +49 (0)7071-923-17

Telefax: $+49(0) 7071-51104$ 